\title{
Distinguishing predisposing factors for enamel hypoplasia and molar-incisor hypomineralization in children in lle-lfe, Nigeria
}

Oluwaseyi Dada Temilola ${ }^{1}$, Morenike Oluwatoyin Folayan ${ }^{2}$

\author{
${ }^{1}$ Obafemi Awolowo University, Teaching Hospitals Complex, Department of Child Dental Health, Ile-Ife, Osun state, Nigeria \\ ${ }^{2}$ Obafemi Awolowo University, Faculty of Dentistry, Oral Habit Study Group, Ile-Ife, Osun state, Nigeria
}

\begin{abstract}
Aim: To determine if the prevalence of enamel hypoplasia, molar-incisor hypomineralisation $(\mathrm{MIH})$ and deciduous molar hypomineralisation $(\mathrm{DMH})$ is associated with the socioeconomic status of the child and to determine the prevalence of enamel hypoplasia and MIH/DMH comorbidity in the study population. Methods: Information was collected on the sex and socioeconomic status of the 1,169 study participants' resident in lle-lfe, Nigeria, recruited through a household survey. The children were clinically examined to assess for the presence of enamel hypoplasia, MIH and DMH. Associations between sex, socioeconomic status and the prevalence of enamel hypoplasia, MIH and DMH were determined. The proportion of children with enamel hypoplasia and MIH/DMH co-morbidity was also determined. Results: Among the 1,169 study participants, 47(4.0\%) had MIH, 15 (1.3\%) had DMH and 161 (13.8\%) had enamel hypoplasia. One (0.09\%) study participant had MIH/DMH co-morbidity, 12 (1.0\%) had DMH/enamel hypoplasia co-morbidity, and $9(0.8 \%)$ had MIH/hypoplasia co-morbidity. There was no significant association between the socioeconomic status and presence of enamel hypoplasia $(p=0.22), \mathrm{MIH}(\mathrm{p}=0.78)$ or $\mathrm{DMH}(\mathrm{p}=1.00)$. Conclusions: The socioeconomic status cannot be used as a distinguishing factor for enamel hypoplasia, MIH and DMH. The possibility of co-existence of enamel hypoplasia and $\mathrm{MIH} / \mathrm{DMH}$ makes it imperative to find ways to distinguish between the lesions.
\end{abstract}

Keywords: dental enamel hypoplasia; child; Nigeria; social class.

\section{Introduction}

Developmental defects of enamel (DDE) are well recognized in the dental literature and defined as any alteration resulting from diverse disturbances during the process of odontogenesis caused by hereditary, local or systemic factors ${ }^{1}$. The primary, permanent or both dentitions may be affected. Lesions may appear opaque due to hypo-mineralization, which causes alteration in the translucency of enamel.

Received for publication: November 15, 2015 Accepted: December 13, 2015

Correspondence to: Morenike Oluwatoyin Folayan Faculty of Dentistry, Obafemi Awolowo University lle-lfe, Osun state, Nigeria Phone: +23-470-6292-0394 E-mail: toyinukpong@yahoo.co.uk These opacities may be white, cream, yellow or brown in color. Lesions may also appear as grooves, pits, partial or total loss of surface enamel, due to quantitative defect in enamel called hypoplasia ${ }^{2-3}$.

It may be difficult to distinguish between hypoplasia and post-eruptive enamel loss ${ }^{4}$. This challenge may be real in regions where the prevalence of enamel hypoplasia and enamel hypomineralization is high. Nigeria is one such country: the prevalence of DDE is approximately $4 \%$ in the primary dentition ${ }^{5}$ and $6.0-$ $11.7 \%$ in the permanent dentition ${ }^{6-7}$. The prevalence of molar-incisor 
hypomineralization (MIH) ranges between $9.7 \%$ and $17.7 \%$ 9 and that of deciduous-molar hypomineralization (DMH) is $4.6 \%{ }^{8}$. The possibility of co-existence of these lesions is therefore high. Little is known or discussed in the literature about the co-existence of enamel hypoplasia and enamel hypomineralization and the implications of these comorbidities for patients' health and welfare.

The etiological factors for DDE are diverse, ranging from birth prematurity to low birth weight, infections, malnutrition or metabolic disorders $\mathrm{s}^{3,10}$. Although the precise cause and effect mechanism has not been clearly elucidated, these enamel defects can have a significant impact on esthetics, tooth sensitivity and occlusal function ${ }^{2,11-13}$. Many of the aetiological factors have a higher incidence in families with low socioeconomic status $\mathrm{s}^{3,10}$. The low prevalence of DDE in developed countries with good nutrition ${ }^{10}$ and the high prevalence in developing countries highlight the possible role of socioeconomic factors as aetiological factor for DDE.

A previous study on DDE in children from Nigeria showed a strong association between socioeconomic status and prevalence of different forms of $\mathrm{DDE}^{6}$. Similar findings have been reported in Tanzania ${ }^{14}$. Another study has also suggested that children from higher socioeconomic groups tend to have more diffuse mottling than children from low socioeconomic group ${ }^{7}$. However, the only study retrievable on the association between MIH and socioeconomic status showed no significant association ${ }^{9}$.

These data suggest that the socioeconomic status may be a distinguishing predisposing factor between enamel hypoplasia and MIH. There is however, no study conducted to determine if the socioeconomic status of a particular population could be used as a distinguishing feature for enamel hypoplasia, MIH and DMH. This study therefore aimed to determine if the prevalence of enamel hypoplasia, MIH and $\mathrm{DMH}$ is associated with the socioeconomic status of the child. It also would determine the prevalence of enamel hypoplasia/ $\mathrm{MIH} / \mathrm{DMH}$ co-morbidities in the study population.

\section{Material and methods}

This is a secondary analysis of a data collected to determine the prevalence of developmental dental hard tissue anomalies in the mixed dentition of children resident in Ile-Ife, Central Local Government Area (LGA), Osun State, Nigeria. The data was collected during the July and August, 2013. The study population, sample size, sampling techniques for determining the prevalence of enamel hypoplasia, $\mathrm{MIH}$ and $\mathrm{DMH}$ have been described in great details in prior study reports ${ }^{8,15}$.

Data were collected by a household survey administered to 1,169 children aged 1 to 19 years old. Children excluded from the study were those who had a medical condition or syndrome that could increase the risk for tooth anomalies such as those who had cleft palate, and those with a history of diseases that could increase the risk for developing dental anomalies, such as maternal syphilis.

Sample size: The sample size required to determine if there was an association between different socioeconomic status and enamel hypoplasia using a prevalence of $18.9 \%{ }^{15}$, to determine if there was an association between different socioeconomic status and $\mathrm{MIH}$ using a prevalence of $19.2 \%{ }^{9}$ and to determine if there was an association between different socioeconomic status and DMH using a prevalence of $4.6 \%{ }^{8}$ is 1,169 .

Data collection tool: Data were collected by personal interview method, using a structured questionnaire. A dentist experienced with normal and pathological dental features and who had been engaged in a similar household dental survey in the same LGA, was engaged as field worker for the study.

Data collected included information on the child's socio-demographic characteristics (sex and socioeconomic status). Socioeconomic status for the purpose of this study was obtained by a multiple item scoring index ${ }^{16}$ used in prior studies in Nigeria ${ }^{17,18}$. The status designation combines the mother's level of education with the occupation of the father; each child was allocated to a social class $\mathrm{I}$ to $\mathrm{V}$, with class $\mathrm{V}$ being the lowest. Each social class was classified as Class I (upper class), class II (upper middle class), class III (middle class), class IV (lower middle class) and class V (lower class).

Clinical examination: All children eligible to participate in the study had an oral examination. The examinations were conducted under natural light, with the children sitting on a chair. The teeth were examined wet, after debris had been removed by use of a piece of gauze, and sterile dental mirrors and probes. The dental mirror was used to further provide illumination of the tooth surfaces through reflection of light and sun. Each fully emerged tooth in the mouth was screened for enamel defects (hypoplasia and hypomineralization) using the Modified DDE Index ${ }^{19}$. Distinction was made between defects that appear as changes in the translucency of enamel (enamel opacity/hypomineralization), or as deficiencies in the quantity of enamel (enamel hypoplasia).

The diagnosis of enamel hypoplasia was made when there was evidence of deficiency in enamel formation seen clinically as pits, grooves or generalized ${ }^{20}$. The diagnosis of MIH was established as MIH or DMH using the criteria described by Kemoli ${ }^{21}$

The coronal part of the second primary molars, permanent first molars and permanent incisors were thoroughly examined for evidence of enamel hypomineralization. A tooth was considered to have MIH or DMH when there was a demarcated opacity of about $2 \mathrm{~mm}$ associated with or without postoperative defects of deficiency in the enamel, large and extensive restorations on any of these teeth and suspected to be a result of hypomineralization. DMH and MIH were diagnosed according to the European Academy of Pediatric Dentistry (EAPD) criteria $^{22}$. A first permanent molar or a second primary molar was diagnosed as having MIH or DMH when at least one of these criteria or a combination was found $^{23}$. Enamel defects were differentiated from carious lesions by their clinical appearance and locations (usually not related to gingival margins or occlusal fissures) ${ }^{2}$. 
Standardization of examiner: An inter-examiner reliability test was done to calibrate the principal investigator on consistency of diagnosis for structural dental defects. The calibration was done by a consultant paedodontist who had worked extensively on MIH and DMH over the last five years. The test was done by examining photographs of hypoplastic teeth and hypomineralized molars and incisors. The inter-examiner reliability score for means MIH was 0.90 and enamel hypoplasia was 0.90 . The inter-examiner reliability score for enamel hypoplasia was 0.75 .

Data Analysis: The socioeconomic status of children was re-categorized into three classes: social classes I and II, high socioeconomic status; social class III, middle socioeconomic status; and social classes IV and V, low socioeconomic status. Descriptive and bivariate analyses were conducted to test the association between dependent variables (enamel hypoplasia, MIH/DMH) and the child's socioeconomic status and sex. Where appropriate, the Pearson's chi-squared test or Fisher's exact test was used to test associations. Univariate logistic regression was also conducted to determine the odds of having enamel hypoplasia, MIH and DMH adjusting for sex and socioeconomic status of the child. Statistical analysis was done with Intercooled STATA (release 12) for Windows. Simple proportions were computed. Statistical significance was inferred at $\mathrm{p}<0.05$.

Ethical consideration: Ethical approval was obtained from the Obafemi Awolowo University Teaching Hospital Complex Ile-Ife (ERC/2013/07/14) on the 27 th of June 2013. Approval for community entry was obtained from the LGA office. Written informed consent was obtained from a parent or legal guardian of each study participant prior to enrollment. Information on the socio-demographic profile of the children was obtained from either the consenting parent or legal guardian and written assent for children 8 years and above.

\section{Results}

There were $575(49.2 \%)$ male and $594(50.8 \%)$ female participants. The mean age of the study participants was $7.2+4.3$ years. The median age was 6 years. Two hundred and fifty $(21.4 \%), 402(34.4 \%)$ and $516(44.2 \%)$ of the respondents were in the high, middle and low socio-economic strata, respectively.

Of the 1,169 study participants, 47 (4.0\%) had MIH, 15 (1.3\%) had DMH and 161 (13.8\%) had enamel hypoplasia. One $(0.09 \%)$ of the study participant had MIH/DMH comorbidity, 12 (1.0\%) had DMH/hypoplasia co-morbidity, and $9(0.8 \%)$ had $\mathrm{MIH} /$ hypoplasia co-morbidity.

Table 1 shows the association between socioeconomic status, MIH, DMH and enamel hypoplasia. There was no significant association between socioeconomic status and presence of enamel hypoplasia $(p=0.22)$, MIH $(p=0.78)$ or DMH $(\mathrm{p}=1.00)$.

Table 2 shows the multivariate logistic regression analysis determining how sex and socioeconomic status predicted presence of enamel hypoplasia, MIH and DMH. The odds of having enamel hypoplasia (AOR: 0.83; CI: 0.59$1.16 ; \mathrm{p}=0.27$ ) and DMH (AOR: 0.69; CI: 0.24 - 1.94; $\mathrm{p}=0.48)$ was lower for females when compared with males though these findings were not significant. The odds of having MIH was higher for females (AOR: 1.07; CI: $0.60-$ $1.93 ; \mathrm{p}=0.81)$ when compared with males though this finding was also not significant.

The odds of having enamel hypoplasia (AOR: 1.36; CI: 0.93-2.00; $\mathrm{p}=0.11$ ) and MIH (AOR: 1.27; CI: $0.65-2.18$; $\mathrm{p}=0.48$ ) was higher for those with lower socioeconomic status when compared with those with high socioeconomic status though these findings were not significant. The odds of having DMH was lower for those with lower socioeconomic status when compared with those with high socioeconomic status (AOR: $0.93 ; \mathrm{CI}: 0.26-3.32 ; \mathrm{p}=0.91$ ) though this finding was also not significant.

Table 1: Association between socioeconomic status, hypoplasia, MIH and DMH of 1169 study participants resident in Nigeria.

\begin{tabular}{|c|c|c|c|c|}
\hline \multirow[b]{2}{*}{ Variables } & \multicolumn{3}{|c|}{$\begin{array}{l}\text { Socioeconomic status } \\
\qquad n=1,169\end{array}$} & \multirow[b]{2}{*}{$p$ value } \\
\hline & $\begin{array}{l}\text { High } \\
n=250 \\
n(\%)\end{array}$ & $\begin{array}{c}\text { Middle } \\
\mathrm{n}=402 \\
\mathrm{n}(\%)\end{array}$ & $\begin{array}{c}\text { Low } \\
n=516 \\
n(\%)\end{array}$ & \\
\hline \multicolumn{5}{|c|}{ Enamel hypoplasia } \\
\hline Absent & $208(83.2 \%)$ & $354(80.1 \%)$ & $445(86.2 \%)$ & 0.22 \\
\hline Present & $42(16.8 \%)$ & 48 (11.9\%) & $71(13.8 \%)$ & \\
\hline \multicolumn{5}{|l|}{ MIH } \\
\hline Absent & $238(95.2 \%)$ & $387(96.3 \%)$ & $496(96.1 \%)$ & 0.78 \\
\hline Present & $12(4.8 \%)$ & $15(3.7 \%)$ & $20(3.9 \%)$ & \\
\hline \multicolumn{5}{|l|}{ DMH } \\
\hline Absent & $247(98.9 \%)$ & $397(98.8 \%)$ & $509(98.6 \%)$ & 1.00 \\
\hline Present & $3(1.2 \%)$ & $5(1.2 \%)$ & $7(1.4 \%)$ & \\
\hline
\end{tabular}


Table 2. Logistic regression analysis for the association between sex, socioeconomic status, enamel hypoplasia, MIH and DMH of 1,169 study participants resident in Nigeria

\begin{tabular}{|c|c|c|c|c|c|}
\hline \multirow[t]{2}{*}{$\begin{array}{l}\text { Independent } \\
\text { Variables }\end{array}$} & \multicolumn{2}{|c|}{$\begin{array}{c}\text { Dependent variables } \\
\mathrm{n}(\%)\end{array}$} & \multicolumn{3}{|c|}{ Multiple regression analysis } \\
\hline & \multicolumn{2}{|c|}{ Enamel hypoplasia } & $\begin{array}{c}\text { Adjusted } \\
\text { odds } \\
\text { ratio }\end{array}$ & $96 \% \mathrm{Cl}$ & $p$ value \\
\hline & Yes & No & & & \\
\hline Sex & 73 (45.3\%) & $501(49.7 \%)$ & - & - & \\
\hline Male & $88(54.7 \%)$ & $507(50.3 \%)$ & 0.83 & $0.59-1.16$ & 0.27 \\
\hline \multicolumn{6}{|l|}{ Female } \\
\hline \multirow{2}{*}{\multicolumn{6}{|c|}{$\begin{array}{l}\text { Socioeconomic } \\
\text { status }\end{array}$}} \\
\hline & & & & & \\
\hline High & $42(26.1 \%)$ & $208(20.6 \%)$ & - & - & \\
\hline Low & $119(73.9 \%)$ & $780(79.4 \%)$ & 1.36 & $0.93-2.00$ & 0.11 \\
\hline \multicolumn{6}{|c|}{ MIH } \\
\hline \multicolumn{6}{|l|}{ Sex } \\
\hline Male & $24(50.0 \%)$ & $550(49.1 \%)$ & - & - & \\
\hline Female & $24(50.0 \%)$ & $571(50.9 \%)$ & 1.07 & $0.60-1.93$ & 0.81 \\
\hline \multirow{2}{*}{\multicolumn{6}{|c|}{$\begin{array}{l}\text { Socioeconomic } \\
\text { status }\end{array}$}} \\
\hline & & & & & \\
\hline High & $35(72.9 \%) 1$ & $238(21.2 \%)$ & - & - & \\
\hline Low & $3(27.1 \%)$ & $883(78.8 \%)$ & 1.27 & $0.65-2.18$ & 0.49 \\
\hline \multicolumn{6}{|c|}{$\mathrm{DMH}$} \\
\hline \multicolumn{6}{|l|}{ Sex } \\
\hline Male & $6(40.0 \%)$ & $569(49.3 \%)$ & - & - & \\
\hline Female & $9(60.0 \%)$ & $585(50.7 \%)$ & 0.69 & $0.24-1.94$ & 0.48 \\
\hline \multirow{2}{*}{\multicolumn{6}{|c|}{$\begin{array}{l}\text { Socioeconomic } \\
\text { status }\end{array}$}} \\
\hline & & & & & \\
\hline High & $3(20.0 \%) 12$ & $247(21.4 \%)$ & - & - & \\
\hline Low & $(80.0 \%)$ & $907(78.6 \%)$ & 0.93 & $0.26-3.32$ & 0.91 \\
\hline
\end{tabular}

MIH: molar-incisor hypomineralisation

DMH: deciduous molar hypomineralisation

\section{Discussion}

The study highlights the non-significant role of sex and socioeconomic status as distinguishing predisposing factors for enamel hypoplasia, MIH and DMH: sex and socioeconomic status were not associated with presence of enamel hypoplasia, MIH or DMH. Neither was sex and socioeconomic status a significant predictive factor for enamel hypoplasia, MIH or DMH. However, the possibility of having both enamel hypoplasia and MIH/DMH comorbidities reinforces the need to identify ways of differentiating the lesions. The prevalence of these comorbidities is low in this study population.

In a study conducted in the same environment, Oyedele et $\mathrm{al}^{9}$ had earlier highlighted that the non-statistical association between socioeconomic status and MIH may be a distinctive feature of MIH and enamel hypoplasia, since prior studies conducted in the country ${ }^{5,6}$ highlighted an association between socioeconomic status and enamel hypoplasia. However, the present study was not able to make such distinction through the tests of associations nor could it establish that the socioeconomic status of study participants could serve as a significant predictor for enamel hypoplasia, MIH or DMH.
One of the strengths of the study is the ability to generalize the findings to the study environment as the participants were recruited by a household survey. This increased the chances of including all segments of the study population in the sampling framework. However, this study was a secondary data analysis not specifically powered to test the hypothesis. As the sample size used for this secondary data analysis exceeded the minimum sample size required to conduct such primary analysis, the study findings are valid. The finding is specific for the study environment and the outcome cannot be generalized beyond the study population.

It can be therefore concluded that for this study population, sex and socioeconomic status are not associated with nor are they predictors of enamel hypoplasia, MIH or DMH. The possibility of co-existence of enamel hypoplasia and MIH, and enamel hypoplasia and DMH makes it imperative to find ways to distinguish between the lesions, especially since the predisposing factors for $\mathrm{MIH} / \mathrm{DMH}$ are poorly understood.

\section{Acknowledgements}

We are grateful to Dr. T Owoeye for his contributions towards the collection of the data for this study. 


\section{References}

1. Robles MJ, Ruiz M, Bravo-Perez M, González E, Peñalver MA. Prevalence of enamel defects in primary and permanent teeth in a group of schoolchildren from Granada (Spain). Med Oral Patol Oral Cir Bucal. 2013; 18:e187-193.

2. Seow WK, Ford D, Kazoullis S, Newman B, Holcombe T. Comparison of enamel defects in the primary and permanent dentitions of children from a low-fluoride District in Australia. Pediatr Dent. 2011; 33: 207-12.

3. Martínez Gómez TP, Guinot Jimeno F, Bellet Dalmau LJ, Giner Tarrida L. Prevalence of molar-incisor hypomineralisation observed using transillumination in a group of children from Barcelona (Spain). Int $\mathrm{J}$ Paediatr Dent. 2012; 22: 100-9.

4. Fearne J, Anderson P, Davis GR. 3D x-ray microscopic study of the extent of variations in enamel density in first permanent molars with idiopathic enamel hypomineralisation. Br Dent J. 2004; 196:634-8.

5. Adenubi JO. Dental Health Status of $4 / 5$ year old children in Lagos private school. Nig Dent J. 1980; 1: 28-39.

6. Enwonwu CO. Influence of socio-economic conditions on dental development in Nigerian children. Arch Oral Biol. 1973; 18: 95-107.

7. Osuji OO, Leake JI, Chipman ML, Nikiforuk G, Locker D, Levine D. Risk factors for dental fluorosis in a fluoridated and non-fluoridated community. J Dent Res. 1988; 67: 1488-92.

8. Temilola DO, Folayan MO, Oyedele TA: The prevalence and pattern of deciduous molar hypomineralization and molar-incisor hypomineralization in children from a suburban population in Nigeria. BMC Oral Health. 2015; $15: 73$.

9. Oyedele TA, Folayan MO, Adekoya-Sofowora CA, Oziegbe EO. Prevalence, pattern and severity of molar incisor hypomineralisation in 8 to 10 year-old children in lle-Ife, Nigeria. Eur Arch Paediatr Dent. 2015; 16:.277-82.

10. Masumo R, Bardsen A, As from NA: Developmental defects of enamel in primary teeth and association with early life course events: a study of 6 36 month old children in Manyara, Tanzania. BMC Oral Health. 2013; 13: 21.

11. Casanova-Rosado AJ, Medina-Solis CE, Casanova-Rosado JF, Vallejos-Sanchez AA, Martinez-Mier EA, Loyola-Rodriguez JP, et al. Association between developmental enamel defects in the primary and permanent dentitions. Eur J Paediatr Dent. 2011, 12: 155-8.

12. Vargas-Ferreira F, Ardenghi TM: Developmental enamel defects and their impact on child oral health-related quality of life. Braz Oral Res. 2011, 25: 531-7.

13. Ford D, Seow WK, Kazoullis S, Holcombe T, Newman B. A controlled study of risk factors for enamel hypoplasia in the permanent teeth. Pediatr Dent. 2009; 31: 382-8.

14. Masumo R, Bårdsen A, Astrøm AN. Developmental defects of enamel in primary teeth and association with early life course events: A study of 6-36 month old children in Manyara, Tanzania. BMC Oral Health. 2013; 13: 21.

15. Temilola DO, Folayan MO, Fatusi O, Chukwumah NM, Onyekaja N, Oziegbe $\mathrm{E}$ et al. The prevalence, pattern and clinical presentation of developmental dental hard-tissue anomalies in children with primary and mix dentition from lle-Ife, Nigeria. BMC Oral Health. 2014, 14: 125.

16. Araoye MO: Research methodology with statistics for health and social science. Ilorin: Nathadex Publisher; 2003. p.115-9.

17. Bernard B: Indices of social classification. In: Merton RK. Social stratification-a comparative analysis of structure and process 2nd ed. Harcourt Brace; 1957. p. 78-185.

18. Olusanya $\mathrm{O}$, Okpere $\mathrm{O}$, Ezimokhai $\mathrm{M}$. The importance of social class in voluntary fertility control in developing country. WestAfr J Med. 1985, 4: 205-12.

19. A review of the developmental defects of enamel index (DDE Index). Commission on Oral Health, Research \& Epidemiology. Report of an FDI Working Group. Int Dent J. 1992; 42: 411-26.
20. Slayton RL, Warren JJ, Kanellis MJ, Levy SM, Islam M. Prevalence of enamel hypoplasia and isolated opacities in the primary dentition. Islam M Pediatr. 2001, 23: 32-6.

21. Kemoli AM. Prevalence of molar incisor hypomineralization in six to eight year olds in two rural divisions in Kenya. EastAfr Med J. 2008, 85: 514-9.

22. Weerheijm KL. Molar incisor hypomineralisation (MIH). Eur J Paediatr Dent. 2003; 4: 114-20.

23. Elfrink ME, ten Cate JM, Jaddoe VW, Hofman A, Moll HA, Veerkamp JS. Deciduous molar hypomineralization and molar incisor hypomineralization. J Dent Res. 2012; 91: 551 